\title{
ARQUEOLOGIA NO BRASIL E PANORAMA ATUAL: \\ OS NÚMEROS DE 11 ANOS DE DIVULGAÇÃO NA FOLHA DE S. PAULO
}

\section{A U T O R}

\section{Glória Tega}

gloriatega@uol.com.br
Graduada em Jornalismo (PUC Campinas), Especialista em Divulgação Científica (NJR/ECA/USP), Mestranda em Divulgação Científica e Cultural (LABJOR/UNICAMP)

\section{R E S U M O}

No presente artigo exponho os resultados obtidos a partir do levantamento quantitativo realizado com objetivo de ter um panorama parcial do que é divulgado na imprensa quando o assunto é Arqueologia. Foram selecionados 933 textos que abordavam questões relativas a essa ciência, publicados no jornal Folha de S. Paulo, ao longo dos anos de 2000 a 2010, que apareceram na ferramenta de busca da versão digital do jornal impresso. Esses textos foram comparados quantitativamente às licenças para a realização de pesquisas arqueológicas emitidas pelo Instituto do Patrimônio Histórico e Artístico Nacional, IPHAN, levantadas por Wichers (2010) e Zanettini (2009).

Palavras chave: Arqueologia, Jornalismo, Análise do Discurso.

\section{A B S T R A C T}

In this article I present the results obtained from the quantitative survey in order to have a partial picture of what is reported in the press when it comes to archeology. 933 texts were selected that addressed issues related to this science, published in the newspaper "Folha de São Paulo", (from 2000 to 2010, which appeared in the search engine of the digital version of the printed newspaper. These texts were compared quantitatively to the licenses to carry out archaeological research issued by the Institute for National Artistic and Historical Heritage, IPHAN raised by Wichers (2010) and Zanettini (2009).

Keywords: Archaeology, Journalism, Discourse Analysis.

\section{N T R O D U Ç Ã O}

A implantação da Portaria 230 do IPHAN, em 17 de dezembro de 2002, passou a exigir que o licenciamento ambiental contemplasse também a pesquisa arqueológica. A medida acabou impulsionando um grande crescimento no que diz respeito a essas pesquisas no Brasil; gerou a criação de empresas especialistas na realização dos licenciamentos de obras; as Universidades também passaram a se adequar para poderem realizar os licenciamentos; a demanda por profissionais arqueólogos aumentou; foram criados cursos de graduação em Arqueologia, enfim, a Arqueologia no Brasil ampliou sua atuação, as pesquisas ganharam espaço dentro e fora das Universidades, configurando-se um mercado de atuação, de trabalho.

A Portaria também estabeleceu medidas que visam a um retorno à sociedade dos resultados obtidos nas pesquisas, tornando a Arqueologia 
mais evidente, chegando à população em forma de palestras, cartilhas escolares, cursos diversos, visitas guiadas aos sítios, museus criados com a cultura material proveniente de pesquisas realizadas para licenciamentos, dentre muitas outras ações que ajudaram a disseminar essa ciência, o que exigiu o envolvimento de profissionais de diversas áreas

Assim, tendo a citada portaria como parâmetro, Zanettini (2009) e Wichers (2010) sistematizaram os dados a respeito da emissão de portarias para a realização das pesquisas arqueológicas no Brasil, dos quais apresento, no gráfico 1, os de Zanettini (2009):

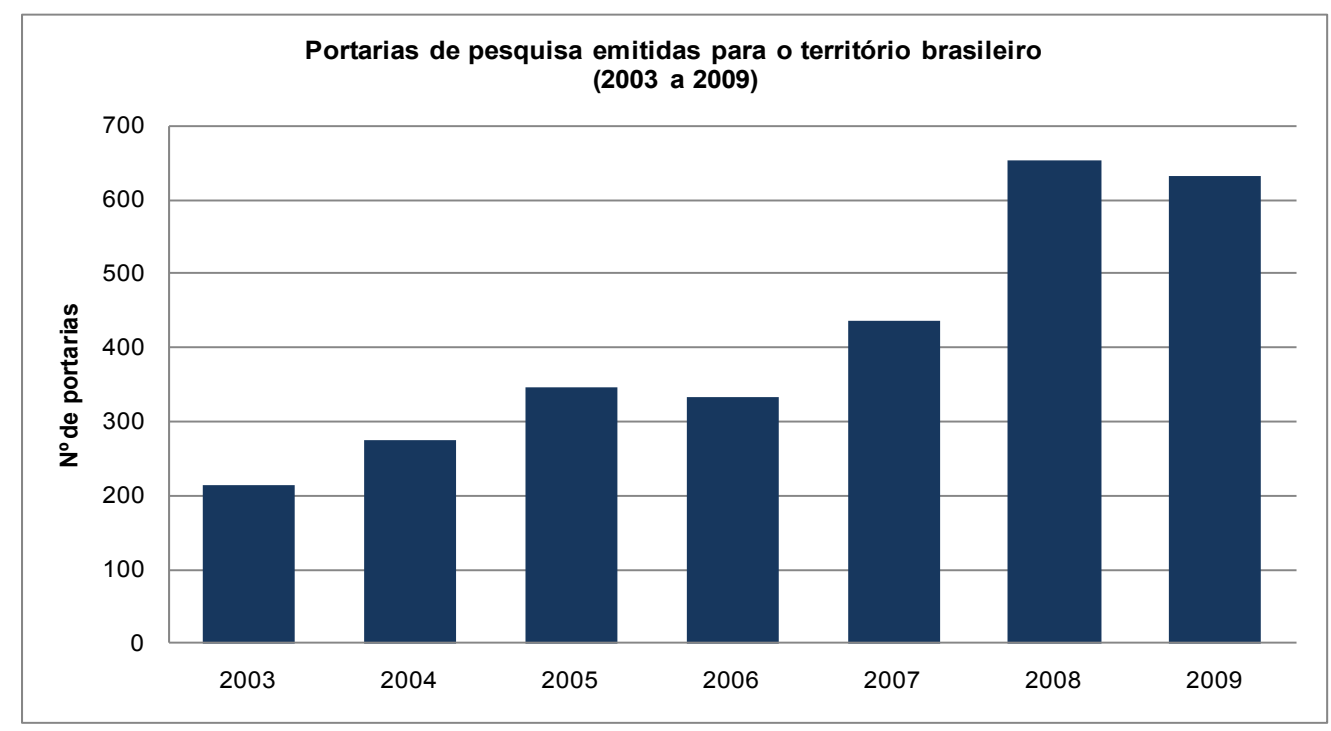

Gráfico 1 - Número de licenças de pesquisa expedidas pelo IPHAN para arqueólogos em território brasileiro (janeiro de 2003 a dezembro de 2009). Fonte: Diário Oficial da União (citado em ZANETTINI, 2009: 76).

1 "Matérias" são textos jornalísticos de diferentes gêneros, como notícia, nota, reportagem, entre outros. Tratase de um "termo genérico usado para qualquer texto que se produz para jornal" (FOLHA, 2010: 82).

\footnotetext{
${ }^{2} \mathrm{~A}$ título de conferência, pedi ao Banco de Dados da Folha de S. Paulo para orçar a mesma pesquisa, procurando no arquivo as mesmas palavras, resultando num custo de $\mathrm{R} \$ 2129,20$, pelas 936 páginas, ou matérias, localizadas. Fazendo manualmente a mesma pesquisa encontrei um total de 933.
}

No período examinado por Zanettini, foram emitidas 3422 portarias de pesquisa arqueológica para o território nacional, englobando portarias de autorização, permissão, prorrogação e renovação, além de portarias voltadas à publicação de normas e orientações. Como mostra o gráfico, existe um aumento relativamente constante no decorrer dos anos no que tange à emissão das portarias de pesquisa, sobretudo, no biênio 2007/2008, com um crescimento de $34 \%$. De acordo com o trabalho citado, grande parte dessas portarias (98\%) está associada ao licenciamento de empreendimentos, configurando um novo campo de atuação da Arqueologia, o da Arqueologia Preventiva.

Partindo do princípio de que o número de pesquisas realizadas no Brasil cresceu de forma tão evidente, o número de textos publicados nos meios de comunicação de massa, os quais, a partir de agora, chamarei também por "matérias"1 , sobre Arqueologia, poderiam ter acompanhado essa tendência, mesmo que o espaço físico destinado às matérias que tratam de ciência seja o mesmo. Para verificar tal possibilidade, fiz um levantamento ${ }^{2}$ das matérias que fazem referência à Arqueologia, publicadas no jornal Folha de S. Paulo.

Primeiramente, para definir um texto como "uma matéria de Arqueologia", partiu-se do conceito formulado por Funari, segundo o qual, "a Arqueologia estuda, diretamente, a totalidade material apropriada pelas sociedades humanas, como parte de uma cultura total, material e imaterial, sem limitações de caráter cronológico" (FUNARI, 2003, 15).

Em segundo lugar, a escolha da Folha se deu porque é um jornal com sede em São Paulo, estado com o maior número de pesquisas arqueológicas 
1 Dados obtidos da Associação Nacional de Jornais. Disponível em http://www.anj.org.br/a-industriajornalistica/jornais-no-brasil/ maiores-jornais-do-brasil. Acesso em 05/04/2011.

${ }^{4} \mathrm{~A}$ pesquisa foi realizada por meio do site www.folha.uol.com.br, entre 08/ 2010 e 02/2011.

realizadas em seu território, de acordo com Wichers (2010), mas também é um jornal de circulação nacional, podendo, inclusive, noticiar as pesquisas arqueológicas realizadas em todo território brasileiro. Além disso, trata-se da maior publicação diária do tipo impresso do Brasil em tiragem, com 295.558 exemplares por dia, em média ${ }^{3}$.

O levantamento começou no ano de 2000, dois anos antes da vigência da Portaria 230 e ano em que o Brasil completou 500 anos do descobrimento, fato que poderia influenciar o número de matérias históricas e/ ou arqueológicas. Foram 11 anos pesquisados, visando também à comparação com os levantamentos de portarias de autorização e permissão emitidas para pesquisas arqueológicas realizados por Wichers (2010) e Zanettini (2009), os quais contemplaram os anos de 2003 a 2009. Terminei o levantamento em 2010, ano em que pude acompanhar o que estava sendo pesquisado e comparar com o que estava sendo publicado.

Foram selecionados textos de todos os gêneros jornalísticos que apareceram na ferramenta de busca da versão digital do jornal ${ }^{4}$, quando procuradas as palavras Arqueologia, Arqueológico, Arqueólogo, Escavação (e variações de gênero e número), para designar a área do conhecimento ou qualificar o sítio de pesquisa ou os objetos pesquisados. Eles foram primeiramente classificados por origem - Brasil ou mundo. Separadas as matérias que se referiam ao Brasil, essas foram classificadas como passíveis de comparação com as portarias de autorização e permissão emitidas para pesquisas pelo IPHAN, as quais foram divididas em pesquisas de Arqueologia preventiva e pesquisas acadêmicas. Na Tabela 1, a seguir, apresento um apanhado geral desse levantamento:

Tabela 1 - Matérias sobre Arqueologia de 2000 a 2010 na Folha de S.

${ }^{5}$ Tal separação foi realizada com o auxílio do arqueólogo Flávio Calippo. Paulo

\begin{tabular}{|c|c|c|c|c|c|c|}
\hline \multirow{2}{*}{ Ano } & \multirow{2}{*}{$\begin{array}{l}\text { Total de } \\
\text { matérias }\end{array}$} & \multirow{2}{*}{$\begin{array}{l}\text { Matérias } \\
\text { sobre } \\
\text { arqueologia } \\
\text { no mundo }\end{array}$} & \multirow{2}{*}{$\begin{array}{c}\text { Matérias } \\
\text { sobre } \\
\text { arqueologia } \\
\text { no Brasil }\end{array}$} & \multicolumn{2}{|c|}{$\begin{array}{l}\text { Comparáveis com portarias de } \\
\text { autorização e permissão }\end{array}$} & \multirow{2}{*}{$\begin{array}{l}\text { Não comparáveis com } \\
\text { portarias de autorização e } \\
\text { permissão }{ }^{6}\end{array}$} \\
\hline & & & & $\begin{array}{c}\text { Relativas ao } \\
\text { licenciamento } \\
\text { de obras }\end{array}$ & $\begin{array}{l}\text { Relativas a } \\
\text { pesquisas } \\
\text { acadêmicas }\end{array}$ & \\
\hline 2000 & 130 & 48 & 82 & 5 & 15 & 62 \\
\hline 2001 & 72 & 45 & 27 & 7 & 4 & 16 \\
\hline 2002 & 85 & 57 & 28 & 7 & 10 & 11 \\
\hline 2003 & 90 & 61 & 29 & 7 & 13 & 9 \\
\hline 2004 & 85 & 57 & 28 & 11 & 6 & 11 \\
\hline 2005 & 86 & 47 & 39 & 8 & 11 & 20 \\
\hline 2006 & 101 & 62 & 39 & 9 & 13 & 17 \\
\hline 2007 & 61 & 44 & 17 & 5 & 3 & 9 \\
\hline 2008 & 56 & 30 & 26 & 3 & 7 & 16 \\
\hline 2009 & 83 & 51 & 32 & 11 & 3 & 18 \\
\hline 2010 & 84 & 55 & 29 & 11 & 5 & 13 \\
\hline
\end{tabular}

6 Muitos textos encontrados tinham como assunto a Arqueologia, mas não eram sobre pesquisas arqueológicas, mas sim sobre cinema, televisão, turismo, exposições, entre outros.
A primeira afirmação que podemos fazer observando a Tabela 1 é que, exceto no ano 2000, o número de matérias que tratam de assuntos relacionados à Arqueologia no mundo sempre foi superior àquelas relativas ao Brasil, assim como sugerem Amorim e Massarani a sobre a "predominância de pesquisas provenientes do exterior nos jornais" (AMORIM \& MASSARANI, 2008: 80), mesmo depois de 2003 quando, suponho, o número de publicações 
já deveria começar a refletir o crescimento no número das pesquisas, pois a portaria 230 foi instituída em dezembro de 2002.

Porém, no ano 2000, o curioso é que não só que o número de matérias sobre a Arqueologia no mundo foi menor que aquelas sobre o Brasil, mas também que, de modo geral, o assunto Arqueologia fez-se mais presente no total de textos publicados, comparado com os demais anos (Gráfico 3). Tais fatos podem ser explicados pelo grande número de matérias relativas às comemorações dos 500 anos do Brasil, o que, possivelmente, desencadeou também várias discussões sobre essa ciência, como na matéria "Encontro analisa a Arqueologia no Brasil". Podemos visualizar esse quadro nos gráficos 3 e 4 a seguir:

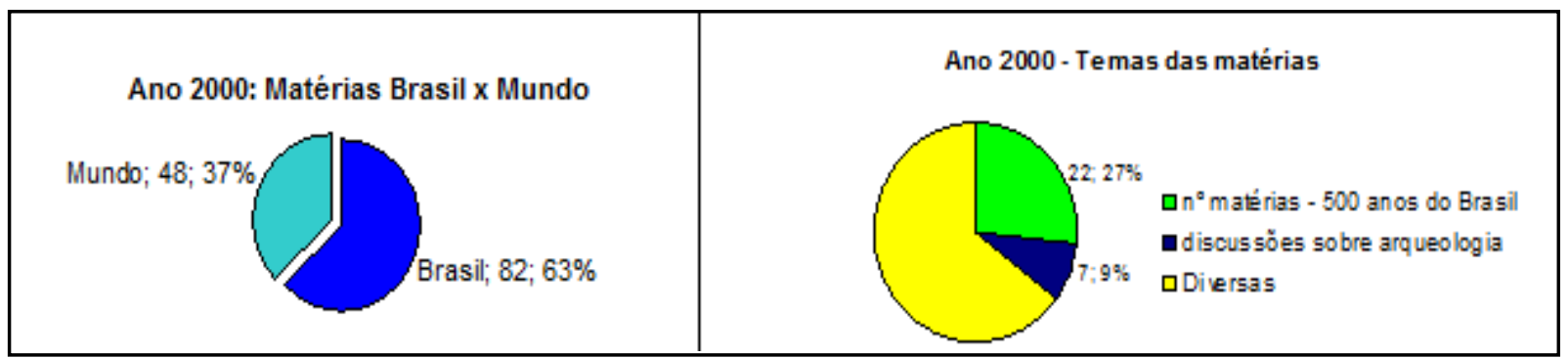

Gráfico 3: Ano 2000, comparativo de matérias Gráfico 4: Ano 2000, comparativo de matérias publicadas na publicadas na Folha de S. Paulo: Brasil x Mundo. Folha de S. Paulo por assunto.

No Gráfico 4 , mais de $25 \%$ das matérias publicadas foram relativas às comemorações dos 500 anos do Brasil e 9\% sobre discussões cujo tema era Arqueologia.

Com o objetivo de se comparar numericamente as matérias publicadas na Folha com o número de portaria emitidas, reproduzo a Tabela 2, sistematizada por Wichers (2010):

Tabela2 - Portarias de pesquisa emitidas para o território brasileiro

\begin{tabular}{|c|c|c|}
\hline Ano & Total de portarias emitidas & $\begin{array}{c}\text { Total de portarias de autorização e } \\
\text { permissão }\end{array}$ \\
\hline 2003 & 269 & 214 \\
\hline 2004 & 327 & 275 \\
\hline 2005 & 397 & 346 \\
\hline 2006 & 397 & 333 \\
\hline 2007 & 507 & 436 \\
\hline 2008 & 771 & 653 \\
\hline 2009 & 754 & 631 \\
\hline Total & $\mathbf{3 . 4 2 2}$ & $\mathbf{2 . 8 8 8}$ \\
\hline
\end{tabular}

A segunda coluna corresponde a todas as portarias de pesquisa emitidas pelo IPHAN e publicadas no Diário Oficial da União entre janeiro de 2003 e dezembro de 2009, totalizando 3.422. Todavia, esse total corresponde a portarias de autorização, permissão, prorrogação e renovação, além de portarias voltadas à publicação de normas e orientações. Por isso, os números contidos na terceira coluna são aqueles que considero relevantes para a comparação direta com as matérias publicadas na Folha, pois correspondem apenas às portarias de autorização e permissão (2888 portarias), e, à realização de pesquisas arqueológicas propriamente ditas, tendo muito mais chance de gerar matérias jornalísticas.

Além disso, voltando à coluna "comparáveis com portarias de autorização e permissão emitidas para pesquisas arqueológicas" da 
Tabela 1 e comparando-a, portanto, com a terceira coluna da Tabela 2, o crescimento relativamente constante observado na segunda, a partir de 2004, não foi constatado na primeira. Na Tabela 1 também é possível notar a inconstância no número de publicações de matérias cujo assunto são pesquisas arqueológicas no Brasil. Mas, como sugere Zanettini (2009), é possível enxergar um leve crescimento a partir de 2004 - não da ordem de $17-20 \%$ ao ano, mas em torno de $11 \%$. Também não é possível notar crescimento algum das matérias publicadas no biênio 2007/2008, período no qual Zanettini observou um pico de crescimento na emissão das portarias. O autor também sugeriu, no início de 2009, que o total de portarias de autorização e permissão emitidas deveria

ultrapassar em 2009 o montante atingido em 2008. Em 2010, talvez venhamos a assistir a um novo boom, sobretudo, se levarmos em conta que apenas $50 \%$ das verbas alocadas para o PAC do Governo federal foram efetivamente utilizadas até o momento (ZANETTINI, 2009: 77).

De fato, ao observarmos as colunas em laranja do Gráfico 5, a seguir, é possível notar que há uma tendência de crescimento no número de matérias publicadas sobre Arqueologia. Mesmo que, em 2007, esse número tenha caído muito em relação a 2006, o gráfico tende a ser ascendente, a partir de 2007.

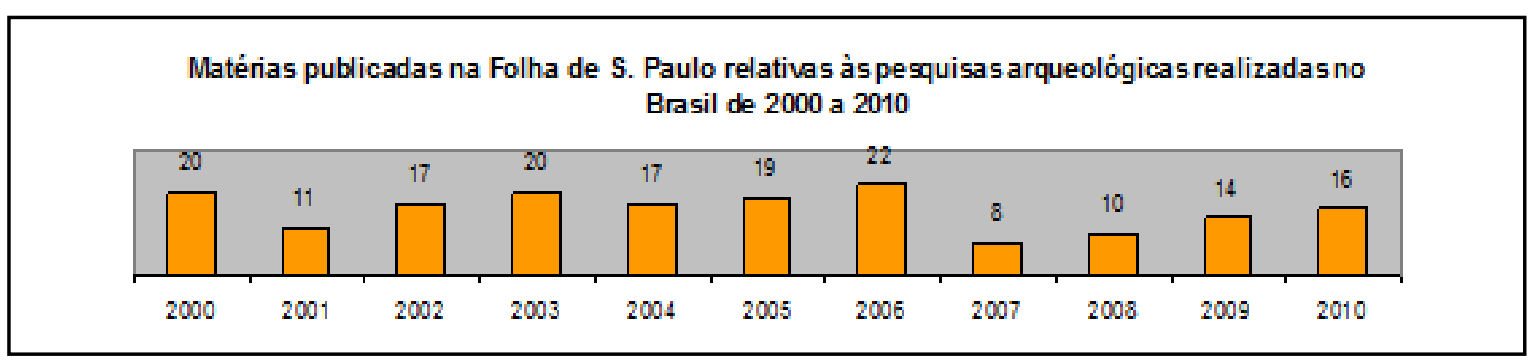

Gráfico 5: Matérias publicadas na Folha de S. Paulo, ano a ano, de 2000 a 2010.

Entretanto, o número de matérias publicadas chega a ser ínfimo perante o número de pesquisas realizadas, quando comparados os mesmos anos dos dois levantamentos, e não acompanha, portanto, o crescimento das pesquisas realizadas no Brasil, que fica facilmente observável quando, no Gráfico 6 a seguir, colocamos o número de portarias de autorização e permissão ( $3^{a}$ coluna da tabela 2 ) e o número de matérias publicadas comparáveis com portarias de autorização e permissão (somatória da $5^{\mathrm{a}} \mathrm{e}$ $6^{a}$ coluna da tabela 1) lado a lado:

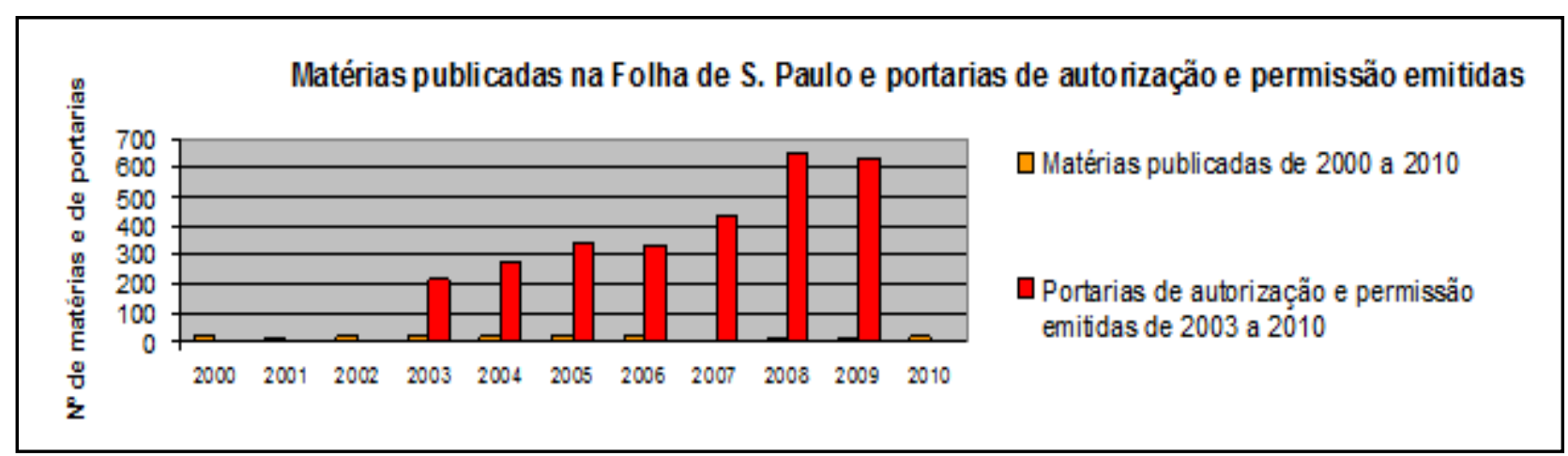

Gráfico 6: Matérias publicadas na Folha de 2000 a 2010 e Portarias .emitidas de autorização e permissão pelo IPHAN entre 2003 e 2009. 
Outra discussão presente na Arqueologia brasileira é a questão da cientificidade ou não da Arqueologia preventiva. Ou seja, o quanto do que é exigido por lei é realizado já que, supostamente, o tempo concedido para a consumação das pesquisas de Arqueologia preventiva não seria o ideal, pois haveria a questão da pressão pela necessidade da realização da obra. Ao contrário, as pesquisas acadêmicas teriam o tempo compatível com a necessidade, já que não sofrem as pressões das construções. Não quero aqui me prolongar em relação a essa discussão, pois esses temas fogem do escopo da minha pesquisa. Faço essa menção apenas para, em primeiro lugar, chamar a atenção ao fato de que por meio dos números que recolhi na Folha, não há a possibilidade de chegar a conclusão alguma a respeito de quais projetos têm maior visibilidade na imprensa, se os de Arqueologia preventiva ou os de Arqueologia acadêmica e, em segundo lugar, porque quis verificar se as matérias seguiam a tendência sugerida por Zanettini (2009), de acordo com o qual a maioria das portarias de autorização e permissão emitidas entre janeiro de 2003 e dezembro de 2009 seria voltada ao atendimento de demandas geradas pelo licenciamento ambiental. Vejamos o Gráfico 7:

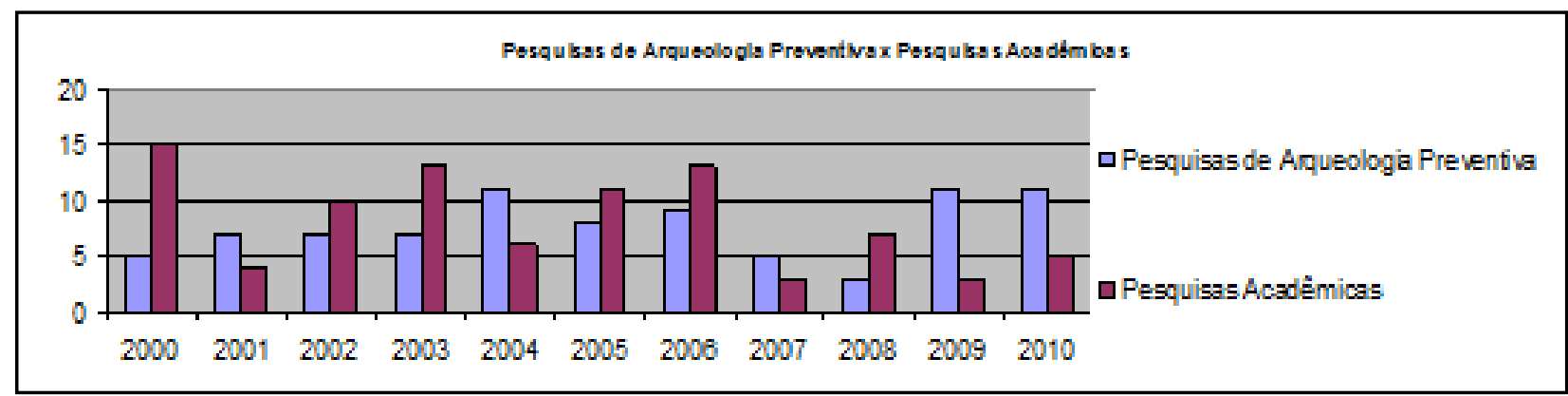

Gráfico 7: Matérias publicadas na Folha de S. Paulo comparáveis com portarias de autorização e permissão emitidas para pesquisas arqueológicas

No período analisado, os anos 2000, 2002, 2003, 2005, 2006 e 2008 possuem maior número de matérias publicadas a respeito da Arqueologia acadêmica. Já nos anos de 2001, 2004, 2007, 2009 e 2010, há mais matérias relativas às pesquisas de Arqueologia preventiva. Aparentemente não há uma explicação para esses números, apenas podemos observar que o ano 2000 é o que tem o maior número de textos publicados sobre pesquisas acadêmicas em todo o período analisado, matérias talvez impulsionadas pelas comemorações dos 500 anos do Brasil - apesar desse número ser quase igual aos obtidos nos anos de 2003 e 2006; nos anos de 2007 e 2008, há um declínio nos textos publicados sobre pesquisas de Arqueologia preventiva; em 2009 e 2010, o número de matérias publicadas sobre pesquisas de Arqueologia preventiva é muito maior que o número daquelas sobre pesquisas acadêmicas. Talvez, aqui, haja de fato um reflexo do crescimento das portarias emitidas, já que, de acordo com Zanettini (2009), atualmente as pesquisas de Arqueologia preventiva respondem por $98 \%$ das portarias de autorização e permissão emitidas pelo IPHAN.

Também é interessante notar que algumas dessas matérias classificadas como relativas a pesquisas de Arqueologia preventiva possuem como principal entrevistado um arqueólogo pertencente a alguma Universidade. Ou seja, são matérias que tratam efetivamente de pesquisas realizadas para o licenciamento de obras, porém quem foi contratado para fazer esse trabalho foi uma Universidade, geralmente pública, como podemos observar no Gráfico 8: 


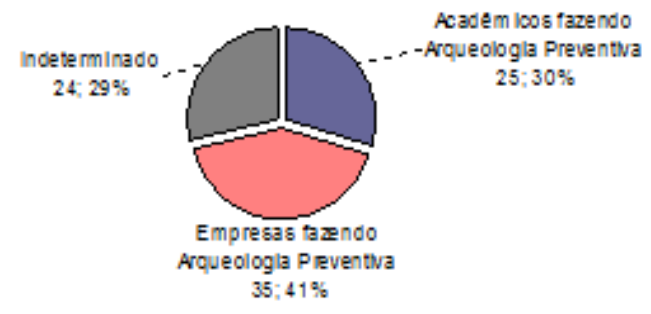

Gráfico 8. Matérias publicadas na Folha de São Paulo relativas às pesquisas de Arqueologia Preventiva sob o aspecto de quem é o principal autor da pesquisa e a instituição a qual ele pertence, de 2000 a 2010.

No Gráfico acima, a categoria 'Indeterminado' é relativa aos textos nos quais não foi possível determinar com exatidão se os pesquisadores citados representavam uma empresa ou uma Universidade. Pensando apenas naquelas matérias em que foi possível determinar a que tipo de instituição os entrevistados pertenciam, é possível dizer que o número de pessoas pertencentes ao meio acadêmico que aparecem em matérias que tratam de pesquisas de Arqueologia de contrato é bastante representativo (30\%). Ou seja, é plausível especular que esse dado tenha origem em três aspectos: primeiro, as assessorias de comunicação das instituições de ensino provavelmente tiveram uma atuação no sentido de divulgar as pesquisas realizadas, mesmo se tratando de pesquisas de Arqueologia preventiva; Segundo, os profissionais envolvidos nas pesquisas possivelmente já são 'fontes' anteriormente consultadas para a elaboração do discurso jornalístico. As fontes são locais ou pessoas que o jornalista busca para obter informações e construir seu texto. No caso das pessoas, são aquelas que, geralmente, o jornalista acostumado a cobrir um determinado tema, no caso ciência, costuma procurar para saber se há algum fato relevante para se tornar notícia, ou seja, há um relacionamento um pouco mais estreito entre jornalista e fonte. É o caso do professor do Museu de Arqueologia e Etnologia da Universidade de São Paulo, Eduardo Góes Neves, comumente procurado para falar de Arqueologia amazônica, seja em relação às suas pesquisas acadêmicas, às suas pesquisas de Arqueologia de contrato ou, até, para dar sua opinião a respeito de outras pesquisas realizadas na região, situações constatadas em diversas matérias desse universo aqui levantado. A Folha classifica suas fontes segundo sua confiabilidade, que

7 A Análise do Discurso de linha francesa será usada posteriormente em alguns dos textos desse levantamento com objetivo de entender o discurso, compreendido como o lugar onde se dão "efeitos de sentidos entre locutores" (ORLANDI, 2007a: 21), pois "é pelo discurso que melhor se compreende a relação entre linguagem/pensamento/mundo, porque o discurso é uma das instâncias materiais (concretas) dessa relação" (ORLANDI, 2007b: 12). vai do "Tipo zero" - a mais confiável - até o "Tipo 4" -a menos confiável. A fonte "Tipo um" é classificada pela Folha como " a mais confiável nos casos em que a fonte é uma pessoa. (...) tem histórico de confiabilidade (...). Fala com conhecimento de causa (...) e não tem interesses imediatos na sua divulgação", (FOLHA, 2010: 38). Acredito que é nesta categoria que se encaixam os arqueólogos pertencentes a instituições de ensino que foram fontes para matérias que tratam de projetos de Arqueologia preventiva. A questão da confiabilidade também pode ter relação com o terceiro aspecto que sugiro para justificar a presença de muitas matérias sobre Arqueologia de contrato encontradas nesse levantamento que foram feitas a partir de entrevistas com arqueólogos pertencentes a alguma Universidade, pois pensando sob a ótica da Análise do Discurso ${ }^{7}$, é coerente afirmar que pode haver um traço de relação de força, já que uma pesquisa de arqueologia preventiva realizada por uma Universidade tem mais 'peso' quando repórter 
busca legitimar, dar credibilidade a seu discurso e, dessa maneira, afirmar a suposta característica do discurso jornalístico como transmissor imparcial da verdade. As relações de força podem ser encontradas nas citações entre aspas também presentes no texto jornalístico, que, de acordo com o Manual de Redação da Folha, seriam "responsáveis pela credibilidade da notícia". Elas dariam a referida credibilidade ao discurso, pois viriam de pessoas autorizadas a falar sobre determinado assunto. Para Maingueneau (1997), o fato de um primeiro locutor se abrigar em um outro discurso seria uma maneira de "sugerir o que se pensa, sem necessitar responsabilizar-se por isso" (MAINGUENEAU, 1997: 86) e, além disso, o locutor citado aparece como a "autoridade que protege a asserção".

Voltando, ainda à Tabela 1, proponho fazer também um recorte e uma reflexão em relação ao número de matérias publicadas de acordo com o estado da federação onde as pesquisas arqueológicas foram realizadas, o que procuro sistematizar na Tabela 4 a seguir:

\begin{tabular}{|l|l|c|c|c|c|c|c|c|c|c|c|c|c|}
\hline \multicolumn{2}{|c|}{} & 2000 & 2001 & 2002 & 2003 & 2004 & 2005 & 2006 & 2007 & 2008 & 2009 & 2010 & TOTAL \\
\hline AC & & & & & & & & 1 & & & 2 & 3 \\
\hline AL & & & & & & 1 & & & & & & 1 \\
\hline AM & 1 & 3 & 1 & 3 & & 1 & 3 & 1 & 1 & & 1 & 15 \\
\hline AP & & & 1 & & & & 2 & & & & & 3 \\
\hline BA & 3 & & 1 & & 1 & & 1 & & & & & 6 \\
\hline CE & & & & & & & 1 & & & & & 1 \\
\hline MG & 2 & & 4 & 3 & 1 & 1 & 1 & & 1 & 1 & & 14 \\
\hline MS & & & & & & & & 1 & & & & 1 \\
\hline MT & & & 2 & 1 & & & & & & & & 3 \\
\hline PA & 2 & & 2 & 1 & 1 & 3 & 2 & 1 & & 2 & & 14 \\
\hline PB & 1 & & 1 & & & & & & & & & 2 \\
\hline PE & & & & 2 & & & & & & & 1 & 3 \\
\hline PI & 2 & & & 2 & 4 & & 4 & 1 & & & 2 & 15 \\
\hline PR & 1 & & & & & & & & & & 1 & 2 \\
\hline RJ & & 1 & & 1 & 3 & 1 & & 1 & 3 & & & 10 \\
\hline RO & & & & & & & & & & 2 & 5 & 7 \\
\hline RS & & 1 & & & & & & & & & & 1 \\
\hline SC & 1 & & & & 1 & 2 & 2 & & & & 1 & 7 \\
\hline SE & & & 1 & & & & & & & & & 1 \\
\hline SP & 6 & 6 & 4 & 6 & 5 & 8 & 6 & 2 & 5 & 9 & 3 & 60 \\
\hline vários & 1 & & & 1 & 1 & 2 & & & & & & 5 \\
\hline TOTAL & 20 & 11 & 17 & 20 & 17 & 19 & 22 & 8 & 10 & 14 & 16 & 174 \\
\hline
\end{tabular}

Tabela 4: Matérias publicadas comparáveis com portarias de autorização e permissão emitidas para pesquisa, ano a ano, por estado da federação.

Cabe dizer que a categoria "vários" corresponde a matérias nas quais vários estados foram citados, como por exemplo, aquelas que se referem ao licenciamento das áreas da Rodovia Transnordestina, que passa por diversos estados do nordeste brasileiro.

De maneira geral, para o período analisado, como já foi apontado em outro momento, o estado de São Paulo é a unidade da federação que mais obteve matérias publicadas a respeito de pesquisas arqueológicas realizadas em seu território (60), seguido de Amazonas e Piauí (15) e, com 14 matérias, os estados do Pará e Minas Gerais. Pelo Mapa 1, a seguir, fica evidente que as áreas das regiões Sudeste e Norte do país destacam-se em relação ao número de matérias publicadas, sendo que, mesmo que timidamente, é possível também notar estados com matérias publicadas na região Nordeste e Sul. Há estados da federação que não tiveram nenhuma matéria publicada. São eles Maranhão, Tocantins, Goiás, Rio Grande do Norte e Espírito Santo, 
mesmo que, de acordo com Wichers (2010), tenham sido realizadas pesquisas arqueológicas entre 2003 e 2009 em seu território. Já no caso do estado de Roraima, Wichers não constatou pesquisas realizadas no período e, assim, isso também acabou se refletindo no levantamento dos textos publicados na Folha.

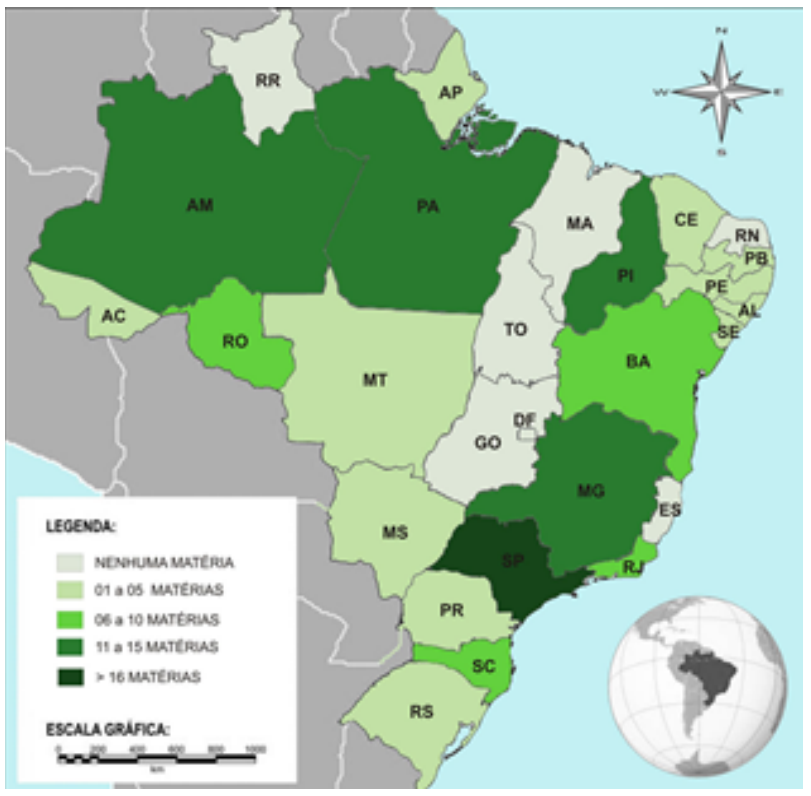

Mapa 1 - distribuição das matérias publicadas na Folha de S. Paulo sobre Arqueologia no Brasil (2000 a 2010).

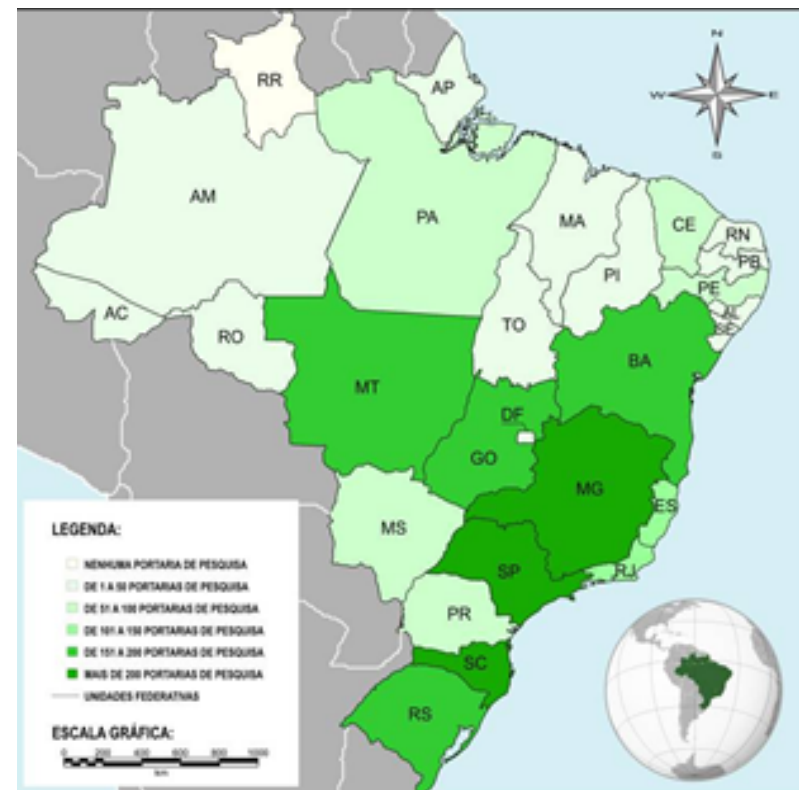

Mapa 2 - distribuição das pesquisas arqueológicas no território brasileiro (2003 a 2009). (WICHERS, 2010, p 204)

No Mapa 2, Wichers (2010) separou as portarias de autorização e permissão emitidas para pesquisas arqueológicas por estado da federação. A autora demonstra que há concentração de portarias de autorização e permissão emitidas para pesquisas nos estados de Mato Grosso, Goiás, Bahia, Minas Gerais, São Paulo, Santa Catarina e Rio Grande do Sul. A partir desses dados, podemos sugerir que o número de pesquisas realizadas em um estado não reflete na publicação de matérias veiculadas na Folha, isso porque os únicos estados que tiveram o número de textos publicados coerente - não numericamente ou proporcionalmente, apenas tendencialmente - com o número de autorizações para pesquisas emitidas foram São Paulo - cabe novamente dizer que o fato do jornal ser paulista, apesar de ter circulação nacional, pode ter influenciado esse dado - e Minas Gerais.

Restringido minha análise aos estados que mais obtiveram publicações no período, observo que na região Norte, de acordo com Wichers (2010), o maior número de portarias de autorização e permissão emitidas ficou com o estado do Pará (84). Já o maior número de matérias para a região Norte foi sobre pesquisas realizadas no estado do Amazonas (15), apenas uma a mais que as que mencionam o Pará (14). Se olharmos para os números de matérias publicadas nos dois estados (total de 29), veremos que a maioria delas não é gerada por pesquisas de Arqueologia preventiva (sete matérias, correspondendo a $24,2 \%$ do total), mas sim por pesquisas acadêmicas (22 matérias, correspondendo a $75,8 \%$ do total). 0 número maior das matérias sobre pesquisas acadêmicas poderia ter sua raiz na maioria das portarias de autorização e permissão emitidas para ambos estados ser de fato para pesquisas acadêmicas. Isso porque eles são ocupados pela Floresta Amazônica, a região do País com maior quantidade de áreas protegidas, tendo mais de um terço de seu território enquadrado em um regime de 
8 Informações retiradas do site http://www.brasil.gov.br/sobre/ meio-ambiente/amazonia/ amazonia/print em 23/05/2011.

9 Informações retiradas do site http://www.fumdham.org.br/, em 18/07/2011.

${ }_{10}$ Informações retiradas do site http://www.fumdham.org.br/, em 18/07/2011. proteção ${ }^{8}$; assim, suponho que o número de obras na região seria limitado. Outro ponto que daria visibilidade às pesquisas de cunho acadêmico é o fato de que há grande número de pesquisas na área é realizada pelo Museu Paraense Emílio Goeldi, instituição com a iniciativa de divulgar suas pesquisas, o que pode ser constatado por meio da manutenção permanente de seu Serviço de Comunicação, onde está inserida a Agência Museu Goeldi, que presta serviços de assessoria de imprensa, entre outras atividades, o que colaboraria para uma maior visibilidade, e se reflete, inclusive, no número de matérias publicadas na Folha. Outro fator que justificaria a predominância de pesquisas acadêmicas seria o interesse científico na região. Para completar é importante ressaltar, ainda, que o interesse da Folha se mostrou bastante grande quando o assunto é a ocupação da Floresta Amazônia, sua antiguidade e o modo de organização das sociedades antigas (15 dentre as 29 matérias tratavam do tema).

Outra observação sobre a região é que Wichers verificou um "um aumento das portarias para o estado de Rondônia (...) nos anos de 2007 e 2008, (...) esse fenômeno está associado à implantação de grandes empreendimentos hidrelétricos e infraestrutura correspondente" (Wichers, 2010: 199). Tal fato pôde também ser observado no levantamento das matérias, pois o estado obteve publicações apenas em 2009 e 2010, após o início da realização das obras, e as sete matérias encontradas sobre Rondônia tratam exatamente de sítios arqueológicos descobertos por ocasião da construção das hidrelétricas citadas.

O Piauí foi um estado brasileiro que também se destacou com o número de matérias publicadas sobre pesquisas arqueológicas em seu território. Porém, Wichers constatou que na região Nordeste, foi a Bahia que registrou o maior número de portarias de autorização e permissão emitidas (200), embora no levantamento da Folha, apenas seis matérias publicadas sobre a Bahia tenham aparecido. Olhando de forma detalhada as matérias publicadas referentes ao Piauí, constatamos que todas as 15 são sobre pesquisas de cunho acadêmico e a respeito do Parque Nacional da Serra da Capivara.

Esse parque está localizado na região sudoeste do estado e possui como atrativo cultural um grande conjunto formado por 912 sítios arqueológicos, fazendo com que a Unesco declarasse-o Patrimônio Cultural da Humanidade, em $1991^{9}$. É na região da Serra da Capivara que existem as datações mais antigas para a ocupação humana no continente americano (100 mil anos), segundo a arqueóloga Niède Guidon, principal pesquisadora da área.

Cabe dizer que Niède Guidon se mostrou a principal entrevistada em quase todas as matérias selecionadas e mais da metade delas discutiam a antiguidade do homem americano, a partir de datações da Serra da Capivara. Suponho que tanto a própria arqueóloga quanto o parque da Serra da Capivara sejam o que há de mais conhecido no Brasil pela população quanto o assunto é Arqueologia. Aqui, vale pontuar que, apesar de seu nome sugerir, Niède Guidon é brasileira e natural de Jaú/SP10 e essa informação torna-se importante quando refletimos sobre as matérias a respeito de Arqueologia publicadas na Folha sob a ótica da Análise do Discurso. Isso porque o fato de Nièd Guidon ser brasileira e não se importar com a frequente atribuição a ela da nacionalidade francesa, é um traço de relação de força que o jornal e/ou a própria arqueóloga usariam para legitimar seus discursos, pois a cientista 
seria uma autoridade inquestionável em virtude de ser uma pesquisadora estrangeira, ou seja, as pesquisas de um cientista estrangeiro teriam maior valor que aquelas realizadas por um brasileiro. Também é possível que esta dedicação da Folha em noticiar as pesquisas de Nièd Guidon, ainda que as datações da cientista para os sítios dessa área sejam controvérsias no meio científico, seja um reflexo da "busca pelo antigo" na mídia, como sugere Wichers:

Os resultados obtidos na Serra da Capivara (as datações) (...) ocupam, frequentemente, espaços na mídia e em grandes exposições de Arqueologia, evidenciando que a busca pelo 'antigo' ainda marca as mentalidades expressas na Arqueologia musealizada brasileira (Wichers, 2010: 225).

Mudando o foco dessa discussão para os estados de São Paulo e Minas Gerais, que aparecem com 60 e 14 publicações na Folha, respectivamente, no levantamento feito por Wichers, a região Sudeste, à qual esses dois estados pertencem, é aquela com o maior número de pesquisas, com 1234 portarias do IPHAN, "o que corresponde a quase metade das portarias de autorização e permissão emitidas no período para o Brasil" (WICHERS, 2010: 201), um dado refletido no levantamento da Folha.

Para o estado de São Paulo, a autora contabilizou 635 portarias de autorização e permissão emitidas para pesquisas no período de 2003 a 2009. No levantamento de matérias publicadas na Folha, o estado também contou com o maior número (60), ou seja, 34,5\% de todas as matérias do período de 2000 a 2010. Wichers afirma que o estado também representa "pelo menos 14\% das pesquisas efetuadas no território nacional" (WICHERS, 2010: 202). Não que haja compatibilidade entre portarias de autorização e permissão emitidas e matérias publicadas, mas podemos sugerir uma certa tendência. É verdade também que, pelo fato de a Folha ter sede em São Paulo, é possível que o número de matérias publicadas sobre as pesquisas realizadas em solo paulista seja explicado pelo que se chama de "proximidade", um dos critérios que os jornalistas utilizam para decidir o que é ou não notícia: "quanto maior a proximidade geográfica entre o fato gerador da notícia e o leitor, mais importante ela é" (FOLHA, 2010: 44) - embora a Folha não divulgue se a tiragem de seus exemplares é maior no estado de São Paulo, é possível deduzir que o maior número de leitores desse jornal de circulação nacional seja paulista.

Apesar disso, o que é interessante notar é que cerca de $68 \%$ das matérias selecionadas para São Paulo foram geradas a partir de pesquisas para o licenciamento de obras, ficando as acadêmicas com cerca de $32 \%$. Wichers não dividiu as portarias que levantou por finalidade acadêmica ou licenciamento de obras, porém ela sugeriu que

a configuração contemporânea da realidade arqueológica brasileira está fortemente imbricada aos processos de crescimento econômico. Dessa forma, os estados que apresentam maior dinâmica econômica, acompanhada de um maior lastro no cumprimento da legislação, foram os mais pesquisados entre 2003 e 2009 (WICHERS, 2010: 202). 
Já o estado de Minas Gerais, o segundo da região Sudeste em emissão de portarias, possui 14 matérias publicadas no período. Dessas, a maioria (13) se refere a pesquisas acadêmicas, dentre as quais apenas uma não tem como assunto as pesquisas realizadas em Lagoa Santa. No local foi encontrado o esqueleto Luzia, que acabou ficando famoso como a brasileira mais antiga da pré-história. A ossada provocou discussões a respeito de como e quando ocorreu o povoamento da América, fazendo com que o assunto "homens de Lagoa Santa" e Luzia tivessem grande destaque na imprensa nacional e internacional.

\section{O N CLUS Ã O}

Comparando o levantamento das portarias de pesquisas arqueológicas emitidas pelo IPHAN de 2003 a 2009, realizado por Zanettini (2009) e Wichers (2010), com o levantamento das matérias que fazem referência à Arqueologia, publicadas no jornal Folha de S. Paulo, entre 2000 e 2010, podemos concluir que as matérias encontradas na Folha no período acompanham apenas tendencialmente as pesquisas realizadas no Brasil. Isso porque se verificou tal tendência somente em aspectos concernentes ao pico de crescimento na emissão das portarias no biênio 2007/2008 e a tendência de aumento na publicação de matérias a partir de 2007. Também concluímos que a falta de pesquisas realizadas no estado de Roraima refletiu-se na falta matérias publicadas sobre esse estado; que as obras de hidroelétricas no estado de Rondônia geraram a publicação de matérias; e que há coerência em relação ao número de pesquisas realizadas no estado de São Paulo e o número de matérias publicadas.

Porém, o número de matérias publicadas no período sobre pesquisas realizadas no mundo ainda é esmagadoramente maior se comparado às matérias que abordam as pesquisas feitas no Brasil, o que poderia ser explicado, talvez, pela publicação de matérias provenientes de agências internacionais de notícias, como a Thomson Reuters, Agence France-Presse, entre outras. A única exceção pôde ser observada no ano 2000 (82 matérias sobre Arqueologia no Brasil e 48 no mundo), porém esse número foi bastante influenciado por textos relativos às comemorações dos 500 anos do Brasil (22), que também pode ter dirigido as pautas a matérias com temas correlacionados.

Além disso, quantitativamente, o número de textos publicados na Folha de S. Paulo não vem acompanhando o grande crescimento das pesquisas em Arqueologia realizadas no Brasil - fica muito longe, aliás. É preciso considerar que a Folha já tem um espaço pré-determinado para as matérias da editoria de ciência; porém, acredito que não há uma regra para a ocupação desse espaço, ou seja, se o jornalista se deparar mais constantemente com interessantes sugestões de pauta sobre as pesquisas arqueológicas, se houver uma postura proativa pela qual o assunto Arqueologia possa chegar até o jornalista da redação, o mesmo espaço disponível será mais vezes ocupado por matérias sobre Arqueologia.

Em relação à divisão entre pesquisas acadêmicas e de Arqueologia preventiva, foi possível verificar que ora há mais matérias que tratam de pesquisas relacionadas ao licenciamento de obras, ora há mais matérias 
sobre pesquisas acadêmicas. Aqui não se pode notar uma tendência de crescimento das publicações a respeito das pesquisas de Arqueologia preventiva após a entrada em vigor da portaria 230 do IPHAN, em 2002. Mas é preciso dizer que, nos últimos dois anos, nota-se que o número de textos sobre pesquisas de Arqueologia preventiva acabou sendo, em 2009, o triplo e, em 2010, o dobro do número de textos sobre pesquisas acadêmicas. Talvez, aqui, observe-se o início da tendência das matérias acompanharem o tipo de pesquisa, já que os projetos de Arqueologia preventiva correspondem hoje à grande parte dos estudos arqueológicos realizados no país.

Podemos fazer especulações para tentar explicar o porquê de o número de publicações na Folha de S. Paulo não ter acompanhado o crescimento das pesquisas, tendencialmente falando - insisto no "tendencialmente", pois jamais o número de matérias publicadas irá se equiparar com o número de portarias de autorização e permissão emitidas. Ouso dizer que, talvez, o número de textos reflita a falta de interesse pela divulgação por parte dos arqueólogos, mas também pode ser reflexo da falta de conhecimento desse universo (Arqueologia, pesquisas acadêmicas e preventivas, onde obter fontes) por parte dos jornalistas, que acabam se interessando pelas mesmas pesquisas científicas, como aquelas realizadas na Serra da Capivara, Lagoa Santa ou Floresta Amazônica, tendo sempre os mesmos arqueólogos como fontes, ou se preocupam apenas em formular matérias que possam retratar o caráter "antigo" e grandes descobertas. Assim como Zanettini observou em 1991, o que ainda pode ser aplicável às matérias selecionadas neste levantamento: "acompanho os noticiários em nossos principais periódicos e o que vejo? Que a múmia mais antiga do mundo já foi descoberta centenas de vezes, que a imprensa escrita devota pouco espaço às descobertas feitas em território nacional" (ZANETTINI, 1991: 4). 


\section{B I B L I O G R A F I A}

AMORIN, Luis Henrique, MASSARANI, Luísa. "Jornalismo Científico: Um estudo de caso de três jornais brasileiros". Revista Brasileira de Ensino de Ciência e Tecnologia vol 1, n 1, jan - abril 2008.

Disponível em http://www.pg.utfpr.edu.br/depog/periodicos/index.php/rbect/article/viewFile/225/198 Acessado em 17/07/2011.

FOLHA DE S. PAULO. Manual da Redação da Folha de S. Paulo. Ed.16. São Paulo, SP: Publifolha, 2010.

FUNARI, Pedro Paulo. Arqueologia. São Paulo,SP : Contexto, 2003.

MAINGUENEAU, Dominique. Novas tendências em análise do discurso. 3ed.Campinas, SP: Pontes, 1997.

ORLANDI, Eni P. Análise do Discurso: Princípios e Procedimentos. Ed. 7. Campinas, SP: Pontes Editores, 2007 a. . Autoria, leitura e feitos do trabalho simbólico. Ed. 5. Campinas, SP: Pontes Editores, 2007 b.

WICHERS, Camila Azevedo de Moraes. Museus e antropofagia do patrimônio arqueológico: caminhos da prática brasileira. 2010. Tese. Programa de Programa de Doutoramento em Museologia. Universidade Lusófona de Humanidades e Tecnologias, Departamento de Museologia., Lisboa, Portugal.

ZANETTINI, Paulo Eduardo. "Projetar o futuro para a Arqueologia Brasileira: desafio de todos". Revista de Arqueologia Americana. Número 27, 2009. (pp 71- 87).

$04-05)$. Paulo Eduardo. "Indiana Jones deve morrer". Jornal da Tarde. São Paulo/SP 18/05/1991. (pp. 